\title{
Social Media Addiction: Applying the DEMATEL Approach
}

\author{
Mohammad Dalvi-Esfahani $^{\mathrm{a}}$, Ali Niknafs ${ }^{\mathrm{b}}$, Daria J. Kuss ${ }^{\mathrm{c}}$, Mehrbakhsh Nilashi,e,**, \\ Saeed Afrough ${ }^{\mathrm{a}}$ \\ a Higher Education Institute of Al-Mahdi, Isfahan, Iran \\ b Department of Information Technology Management, Faculty of Management and \\ Economics, Tarbiat Modares University, Tehran, Iran \\ c Department of Psychology, Nottingham Trent University, 50 Shakespeare Street, \\ Nottingham NG1 4FQ, United Kingdom \\ d Department for Management of Science and Technology Development, Ton Duc \\ Thang University, Ho Chi Minh City, Viet Nam \\ e Faculty of Information Technology, Ton Duc Thang University, Ho Chi Minh City, \\ Viet Nam
}

Telematics and Informatics. https://doi.org/10.1016/j.tele.2019.101250

Received 14 March 2019; Received in revised form 4 June 2019; Accepted 16 July 2019

\begin{abstract}
While there is a growing number of studies investigating the determinants of social media addiction, there is a lack of research on examining the importance of such predictors and their inter-correlations and inter-dependences from psychotherapists' and researchers' point of views. Hence, utilizing the "Decision Making Trial and Evaluation Laboratory (DEMATEL)" technique, the current study investigated the clinical importance of social media addiction from the perspective of researchers and psychotherapists. Accordingly, by reviewing the literature 15 distal predictors of social media addiction were extracted and further classified into three groups of personality factors, comorbid symptoms, and psychosocial factors. From the data collected from 35 respondents, the results highlighted the group of personality factors as the most important dimension increasing the risk for developing social media addiction from the respondents' perspective. Moreover, the DEMATEL results revealed the predictors of openness to experience (personality dimension), loneliness (psychosocial), and depression (comorbid) as the most important predictors of social media addiction within each group. The results and implications of the study are discussed.
\end{abstract}

Keywords: Social media addiction; DEMATEL; Adolescent; Personality; Psychosocial; Comorbidity 


\section{Introduction}

While the term "Internet Addiction" was first introduced by Goldberg (1996), the psychiatrist Young (1996) registered this area of research under her name with the first report of Pathological Internet Use (PIU) observed in a forty-three years old householder with more than sixty hours of being online per week. Afterward, several researchers started to contribute to the body of knowledge by investigating various types of Internet Addiction (IA) and PIU disorders (e.g., Griffiths, 2000; Hardie and Tee, 2007; Jun and Choi, 2015; Kuss and Griffiths, 2015; Mitchell, 2000; Pantic et al., 2017; Young, 1998). Regardless of the proliferation of studies in these areas, the status of PIU/IA is still unknown in the Diagnostic and Statistical Manual of Mental Disorders (DSM). However, recently, DSM-5 included Internet Gaming Disorder (IGD) in its appendix under the section of "conditions for further study" which reflects the importance gained by experts for such addictive behaviors.

With the proliferation of social media tools in the recent decade, research has emerged assessing the possibility of excessive and addictive social media use (e.g., Blackwell et al., 2017; Kurcaburun and Griffiths, 2018; Kuss and Griffiths, 2017; Turel et al., 2018). Furthermore, with the prevalence of mobile devices and the capability of accessing social media tools anytime anywhere, frequent usage has become the norm (Kuss, 2017), with some individuals overusing social media to the extent that addiction symptoms can be the consequence (Dhir et al., 2018; van den Eijnden et al., 2016). In the context of the present paper, social media addiction refers to social media use which causes significant impairment in an individual's life to the extent that they are unable to control their behavior which in turn interferes significantly with everyday life tasks (Ryan et al., 2014).

Research on social media addiction suggests that adolescents are more at risk of developing addiction symptoms as a consequence of their social media use (Kuss and Griffiths, 2017). Accordingly, a growing number of scholars study the predictors of social media addiction among younger generations to further understand the causes of their excessive use resulting in addiction symptoms (e.g., Dhir et al., 2017; Jia et al., 2017; Oberst et al., 2017). While some scholars investigated the associations between social media addiction and personality traits (e.g., Błachnio et al., 2017; Tang et al., 2016), others assessed social media addiction using various theories and models such as uses and gratification motives (e.g., Kircaburun et al., 2018), fear of missing out (e.g., Blackwell et al., 2017), life satisfaction (e.g., Longstreet and Brooks, 2017), self-esteem (e.g., Błachnio et al., 2016b), and depression (e.g., Donnelly and Kuss, 2016), among others. Such studies applied empirical analyses from the perspective of social media users, and specifically, young individuals, to understand to what extent these predictors affect addictive behaviors.

\subsection{Statement of the problem and motivation}

The growing volume of research on social media addiction suggests that such addictive behavior is a type of psychosocial disorder characterized by signs of withdrawal, emotional disturbances, and interruptions of social relationships. Therefore, considering the negative effects of Internet addiction, and to be specific social media addiction, on mental health and academic/job performance of individuals, the need for a comprehensive review of the influential factors is imperative and important.

According to the contemporary body of knowledge, there is a scarcity of studies exploring the determinants of social media addiction among adolescents from the perspective of the Internet 
and social media addiction therapy experts and researchers. To be more specific, while there is a growing number of studies investigating the determinants of social media addiction, there is a lack of research on examining the importance of such predictors and their correlations and interdependences from psychotherapists' and researchers' points of views, as the ones familiar with the field. Kuss and Griffiths (2015) were the only researchers who conducted a qualitative study to explore Internet addiction treatment by interviewing twenty psychotherapists from six countries to further understand their individual experience of treating Internet addicts.

Utilizing the "Decision Making Trial and Evaluation Laboratory (DEMATEL)", the present study attempts to assess the clinical importance of social media addiction from researchers and psychotherapist' point of views. The DEMATEL technique is useful in analyzing the cause and effect associations between the components of a system. The method investigates the contextual interrelationship between the factors under investigation to further solve the complicated problems in the system under investigation. The DEMATEL method not only reveals the relationships among the factors, but also it highlights the critical ones in the system (Zhang et al., 2019). Capabilities of the DEMATEL method approach have resulted in its vast application in various research disciplines. However, to the best of our knowledge, there is no study in the literature applied this method in the context of social media addiction and its related predictors.

Hence, the present study aims to answer the following questions:

(1) What are the predictors of adolescents' social media addiction?

(2) What are the associations between social media addiction and such predictors?

Answering these questions can help understand and describe social media addiction more accurately through direct and indirect relationships between the determinants and can further help developing insights into the collective understanding of these relationships.

\section{$2 \quad$ Literature Review}

\subsection{Social media addiction}

As a result of the social media revolution, researchers have turned their attention to another type of addictive behavior, known as social media addiction (Kuss and Griffiths, 2011). Taken from the addiction paradigm, Andreassen and Pallesen (2014) defined social media addiction as being too worried about social networking sites, driven by a strong incentive to enter or use social networking sites, and devoting enormous time and effort to social networking sites that interfere with other social activities, studies/work, interpersonal relationships, or mental health and wellbeing.

This definition reflects the addiction criteria in previous studies (Griffiths, 2005). Researchers argue that addicts to social media often spend a lot of time thinking about such media and how they can spend more time to use these sites and applications (Salience). Often, they spend more time on such media than the initial intention, feeling that there is an urgent need for more and more use to achieve the same level of enjoyment (Tolerance). Usually, they use social media to reduce feelings of guilt, anxiety, restlessness, and depression, as well as to forget personal problems (Mood modifications). If using social media is prohibited, addicts are often distracted, restless, disturbed, or irritable, and feel uncomfortable if they cannot re-engage in social media (Withdrawal). They do not listen to the advice of others to reduce the time spent on social media. However, their action to cut off social networking activities fails. When they decide to use less social media than before, they fail to manage in this direction (Relapse). Social media addicts give 
less priority to hobbies, studies/work, recreational activities, and sports, and ignore spouse, family members, and friends for social media activities (Conflict). Social media addicts often use such media excessively that have a negative impact on their health, sleep quality, relationships, and well-being (Problem).

\subsection{Background of the study}

In 2001, Davis introduced a cognitive-behavioral model for PIU distinguishing generalized and specific PIUs (Davis, 2001). Generalized PIU refers to the general overuse of the Internet such as spending too much time over the net without a clear objective. However, specific PIU reflects the dependency of an individual to a specific function of the Internet such as online gambling or social networking sites. From then on, several researchers started to investigate the factors influencing generalized PIU (e.g., Ha et al., 2006; Hardie and Tee, 2007; Lam et al., 2009; Song et al., 2004) and specific PIU such as IGD (Hussain et al., 2015; Tian et al., 2018; Wichstrom et al., 2019), gambling (Chóliz et al., 2019; Sirola et al., 2019), social media addiction (Kircaburun et al., 2018; Liu and Ma, 2018; Turel et al., 2018) and cybersex addiction (de Alarcón et al., 2019; Fraumeni-McBride, 2019).

"Uses and Gratifications" theory has been vastly applied to investigate the factors affecting users of social media tools and applications (e.g., Balakrishnan and Shamim, 2013; Gruzd et al., 2016; Kircaburun et al., 2018; Quan-Haase and Young, 2010; Smock et al., 2011). This theory seeks to understand the motives of using different types of media. Williams and Whiting (2013) in their study listed ten gratifications of using social media as "social interaction, information seeking, pass time, entertainment, relaxation, communicatory utility, convenience utility, expression of opinion, information sharing, and surveillance/knowledge about others". In another study by Zolkepli et al. (2018), the authors classified the gratifications of social media utilization into three gratification groups of "personal", "social" and "tension release". They have concluded that social gratifications of "social influence" and "social interaction" were explaining the greater portion of utilization variance.

Brand et al. (2014) developed theoretical models of generic and specific Internet addiction. In their model of specific Internet addiction, they have highlighted that one's core characteristics such as personality traits, demographics, needs, and specific predispositions are influencing her specific cognitions of Internet use. The cognitions are consequently leading to the use of a specific Internet application. The authors highlighted that such predispositions and cognitions are further satisfying some certain desires (i.e. gratifications) which would increase the frequent use of such applications, assumed as addictive behavior in general.

In an earlier model of PIU, Davis (2001) developed a theoretical model of PIU based on the diathesis-stress framework. The author argued "[...] psychopathology is a distal necessary cause of symptoms for PIU" (p. 190). To be more specific, symptoms of PIU occur if psychopathology is already present. The more proximal etiologies of PIU were recognized as maladaptive cognitions. Factors such as low self-esteem and low self-efficacy are necessary for the person to show PIU symptoms.

Brand et al. (2016) revised the specific Internet addiction model (Brand et al., 2014) called Interaction of Person-Affect-Cognition-Execution (I-PACE) model to elicit more determinant of specific Internet addiction. According to their model, the most distal predictors of specific Internet addiction are person's personality (e.g., impulsivity and low self-esteem), social cognitions (e.g., loneliness), psychopathology (e.g., depression), and specific motives (e.g., gambling or games). 
Moving further through the model, once the situation is perceived subjectively and responded to affections and cognitions, the person would decide to use a specific application which to experience gratifications and pleasures.

From the previous studies, it can be concluded that scholars have investigated both distal and proximal determinants of specific Internet use disorder. However, for the current study, the focus is on more distal predictors, which are considered as root causes of addictive behavior (Brand et al., 2014; Brand et al., 2016; Young and Brand, 2017). In the following section more frequent cited predictors of social media addiction are retrieved from the literature and are further explained.

\subsection{Predictors of social media addiction}

Fear of missing out (FOMO) is defined as "a pervasive apprehension that others might be having rewarding experiences from which one is absent" (Przybylski et al., 2013, p. 1841). It was found that there is a direct relationship between FOMO and greater engagement with Facebook (Przybylski et al., 2013), problematic smartphone use (Wolniewicz et al., 2018), social media addiction (Blackwell et al., 2017) and online social media fatigue (Dhir et al., 2018).

Compulsive use behavior is highlighted as another predictor of social media addiction and is defined as "an abnormality in controlling behavioral consumptions where an individual is unable to rationally manage his/her routine performances" (Dhir et al., 2018, p. 143). Scholars have reported that compulsive use behavior directly predicts social media fatigue (Dhir et al., 2018), social media addiction (Liu and Ma, 2018), and smartphone addiction (Lin et al., 2017).

Self-esteem has been defined as "an evaluation of one's self-concept, heavily dependent on reflected appraisals, social comparisons, and self-attributions" (Lemmens et al., 2015). It was reported that there is a direct and negative correlation between self-esteem and Internet Gaming Disorder (Lemmens et al., 2015), social media addiction (van den Eijnden et al., 2016), and Internet addiction (Nie et al., 2017). Specifically, people with lower levels of self-esteem appear to be more prone to addictive behaviors.

Attention deficit disorder is recognized as another determinant of social media addiction (Shaw and Black, 2008; van den Eijnden et al., 2016) and refers to difficulties in inhibiting behavior, inattention and difficulty of staying focused on a specific task. Problematic online gamers show symptoms of attention deficit disorder in comparison to recreational gamers without gaming-related problems (Gentile et al., 2011). Furthermore, in a study by van den Eijnden et al. (2016), the authors reported that there is a direct and positive correlation between attention deficit disorder and addiction to social media.

Impulsivity, which is recognized as an important risk factor for various addictive behaviors (Wu et al., 2013), is considered as one of the predictors of social media addiction in the current study. Impulsive individuals tend to act on a whim and without forethought. For example, in a study conducted by Wu et al. (2013), the authors reported that impulsive individuals are more prone to visit social media via smartphones and hence experience addiction symptoms.

Loneliness, is defined as "an unpleasant experience that derives from important deficiencies in a person's network of social relationships" (Lemmens et al., 2015), and has been identified as an important factor impacting on one's addiction to online gaming (Lemmens et al., 2015), Facebook (Błachnio et al., 2016a), Internet (Hardie and Tee, 2007), and social media use (van den Eijnden et al., 2016).

Personality traits and their role in social media addiction have been explored vastly by several researchers (e.g., Błachnio et al., 2017; Kuss et al., 2013a; Kuss et al., 2013b; Tang et al., 
2016). For example, Kurcaburun and Griffiths (2018) reported that the personality traits agreeableness, conscientiousness, and neuroticism were associated with problematic use of social media among adolescents.

Narcissism was found to be positively related to the Internet and social media addiction (e.g., Andreassen et al., 2016; Błachnio and Przepiórka, 2018; Pantic et al., 2017). Regarding social media addiction, narcissistic individuals use social media to excess to obtain rewards in the form of "likes" and positive comments from their followers (Andreassen et al., 2016).

Life satisfaction, defined as "cognitive assessment of a person's subjective well-being" (Lemmens et al., 2015, p. 3), and its relationship with social media addiction has seen mixed results depending on the respective age group that has been assessed. In a recent study conducted by Teo and Lee (2016), researchers reported that sharing information on social media is experienced as satisfying for younger adults, while the opposite was true for older adult users. In another study by Longstreet and Brooks (2017), the authors showed that the level of life satisfaction negatively correlated with Internet addiction and social media addiction, in that users with lower levels of life satisfaction tend to experience higher levels of Internet and social media addiction.

Several studies reported depression as one of the consequences of social media addiction. For example, Donnelly and Kuss (2016) showed that Instagram use and social media addiction were significant determinants of depression. However, other studies highlighted depression as an important predictor of social media addiction (e.g., Hong et al., 2014; Koc and Gulyagci, 2013).

Table 1: Predictors of social media addiction

\begin{tabular}{|c|c|c|}
\hline Predictor & Addiction context & Source(s) \\
\hline Fear of missing out & Facebook, social media & $\begin{array}{l}\text { Błachnio and Przepiórka (2018), } \\
\text { Blackwell et al. (2017), Dhir et al. } \\
\text { (2018) }\end{array}$ \\
\hline Compulsive use & Social media & $\begin{array}{l}\text { van den Eijnden et al. (2016), Dhir } \\
\text { et al. (2018) }\end{array}$ \\
\hline Self-esteem & Internet, Facebook, Social media & $\begin{array}{l}\text { Pantic et al. (2017), Błachnio et al. } \\
\text { (2016b), Błachnio and Przepiorka } \\
(2016) \text {, Andreassen } \text { et al. (2016) }\end{array}$ \\
\hline Attention deficit & Social media & van den Eijnden et al. (2016) \\
\hline Impulsivity & Social media & van den Eijnden et al. (2016) \\
\hline Loneliness & Facebook, Social media & $\begin{array}{l}\text { Błachnio et al. (2016a), Yu et al. } \\
\text { (2016) }\end{array}$ \\
\hline Personality traits & Internet, Facebook & $\begin{array}{l}\text { Zhou et al. (2017), Jiang et al. } \\
\text { (2017), Grammenos et al. (2017), } \\
\text { Błachnio et al. (2017), Tang et al. } \\
\text { (2016), Kayiş et al. (2016), Błachnio } \\
\text { and Przepiorka (2016), Sariyska et } \\
\text { al. (2014) }\end{array}$ \\
\hline Narcissism & Facebook, Internet, Social media & $\begin{array}{l}\text { Błachnio and Przepiórka (2018), } \\
\text { Pantic et al. (2017), Andreassen et } \\
\text { al. }(2016)\end{array}$ \\
\hline Life satisfaction & Facebook & $\begin{array}{l}\text { Błachnio and Przepiórka (2018), } \\
\text { Błachnio et al. (2016b), Błachnio } \\
\text { and Przepiorka (2016), Satici and } \\
\text { Uysal (2015) }\end{array}$ \\
\hline Depression & Facebook & Błachnio et al. (2015) \\
\hline Empathy & Internet, Smartphone & $\begin{array}{l}\text { Jiaojiao et al. (2017), Lachmann et } \\
\text { al. (2018) }\end{array}$ \\
\hline
\end{tabular}


Hong and Chiu (2014) reported that depression significantly determines Facebook usage patterns of university students and increases their addictive behavior.

Empathy has been recognized as an important factor in explaining one's psychological states (Jeong et al., 2015). Few studies investigated the association between empathy and various technology addiction behaviors. For example, researchers reported that a lower level of empathy is positively associated with Internet and smartphone use disorders (Jiaojiao et al., 2017; Lachmann et al., 2018). Hence, in the current study, empathy is considered as an important determinant of social media addiction. Table 1 summarizes the predictors of social media addiction.

\section{Research model using the DEMATEL format}

Following the study by Kuss et al. (2014), extracted determinants are grouped into three categories of "psychosocial factors", "comorbid symptoms", and "personality factors". Internal characteristics of social media addiction, such as low life satisfaction, loneliness, low self-esteem, FoMo, and empathy, form the dimension of psychosocial factors. Psychopathological symptoms associated with social media addiction, such as attention deficit, depression, compulsivity, and impulsivity, were grouped under the dimension of comorbid symptoms. Finally, the dimension of personality factors are included in the personality traits of social media addicted persons, including as agreeableness, conscientiousness, neuroticism, openness to experience, extraversion, and 


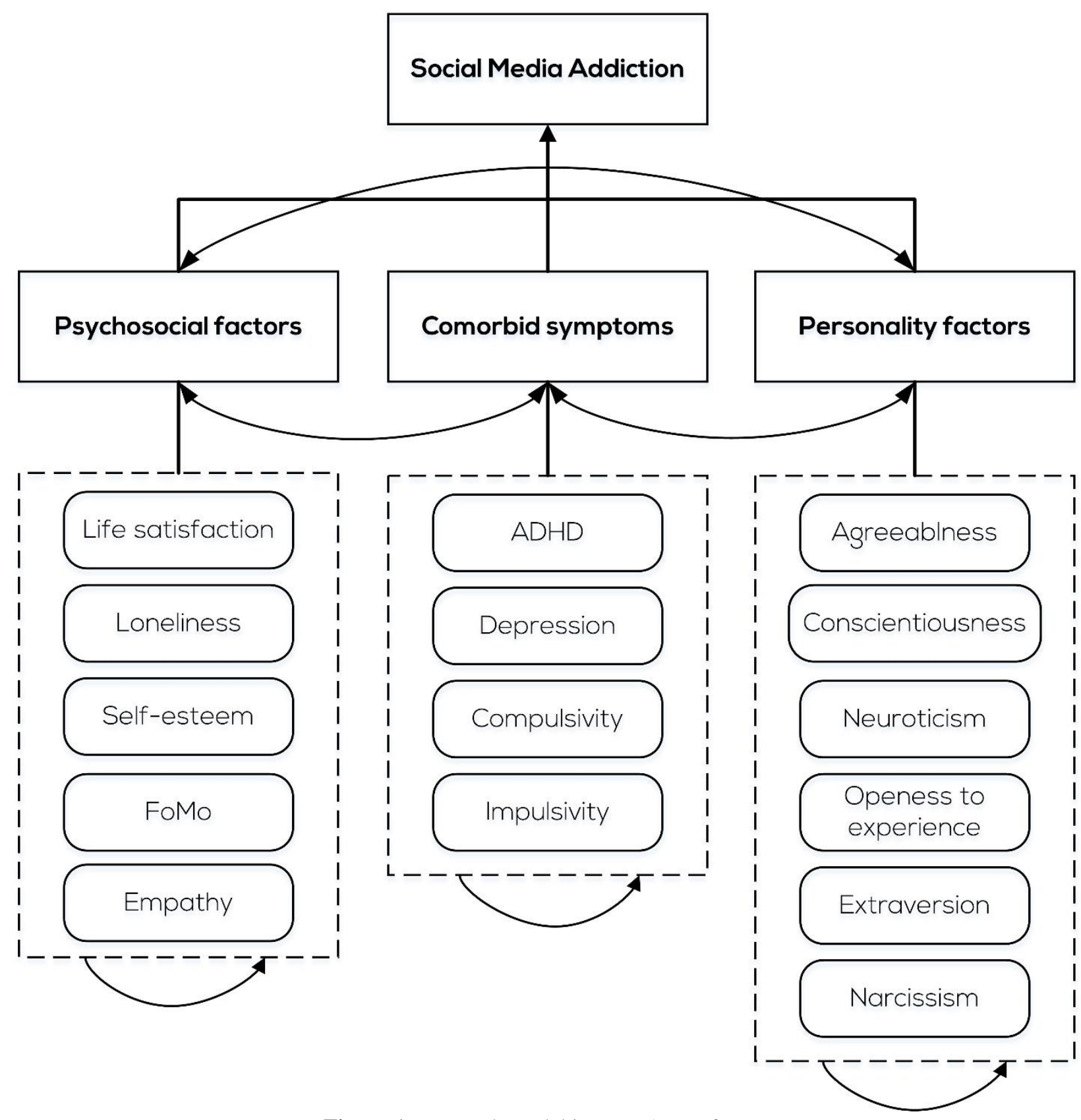

Figure 1: Research model in DEMATEL format

narcissism. According to the groups discussed, the research model of the study in the DEMATEL format is depicted in Figure 1.

\section{$4 \quad$ Methodology}

\subsection{DEMATEL}

In the early 1970s, Duval et al. (1974) developed a method called the "Decision Making Trial and Evaluation Laboratory (DEMATEL)" at the Battelle Memorial Institute of Geneva Research Centre. This method was initially developed to solve real-world complex problems by considering and analyzing several dimensions and several factors involving many stakeholders. 
As a type of structural modeling method, DEMATEL is used to analyze and reveal the cause and effect association between the components of a system. The DEMATEL method is applied to analyze variables impacting a specific system and utilize experts' knowledge to better understand interrelations and inter-dependences between factors. The method not only converts the interdependencies of factors into cause-and-effect relationships but also determines the critical components of a system aided by impact relation diagrams.

To use the DEMATEL method, first the complex system should be defined, then factors (variables in the DEMATEL method) influencing the system should be identified. It is achieved by reviewing the literature or by using experts' opinions. In addition, a measurement scale should be developed to express the relationships and relationship strengths between these factors (Shen et al., 2011). A typical range of scales for this purpose is 0 to 4 denoting "no influence", "low influence", "medium influence", "high influence", and "very high influence", respectively. Respondents were asked to determine the impact of each predictor on the other each predictor of social media addiction.

According to Sumrit and Anuntavoranich (2013), researchers are advised to perform the following steps to apply the DEMATEL method:

Step 1: Gathering experts' opinions

The first step of the DEMATEL approach focuses on collating opinions of $l$ experts $E=$ $\left\{E_{1}, E_{2} \ldots . E_{l}\right\}$ regarding the influence of factors $F=\left\{F_{1}, F_{2} \ldots . F_{n}\right\}$ on each other using the aforementioned scaling system by creating a pair-wise comparison matrix. The $k$ th expert provides an individual direct influence matrix $Z_{k}=\left[z_{i j}^{k}\right]_{n \times n}$ with the zero-value of all principal diagonal elements, $z_{i j}^{k}$ represents the opinion of an expert $E_{k}$ regarding the degree to which the determinant $F_{i}$ influences the determinant $F_{j}$.

Step 2: Compute $Z$ : average matrix

The average matrix $Z=\left[Z_{i j}\right]_{n \times n}$ is computed in order to integrate the opinions of $l$ experts as follows:

$$
z_{i j}=\frac{1}{l} \sum_{k=1}^{l} z_{i j}^{k} . \quad i, j=1,2, \ldots, n
$$

Step 3: Computing normalized influence matrix $X$

Upon the calculation of average matrix $Z$, the normalized matrix $X=\left[x_{i j}\right]_{n \times n}$ is obtained using

$$
X=\frac{Z}{S}
$$

where,

$$
s=\max \left(\max _{1 \leq i \leq n} \sum_{j=1}^{n} z_{i j}, \max _{1 \leq i \leq n} \sum_{i=1}^{n} z_{i j}\right)
$$

Step 4: Computing total influence matrix $T$

Experts only estimated the direct influence of factors on each other. Hence, the total influence matrix $T=\left[t_{i j}\right]_{n \times n}$ is obtained from matrix $X$ by applying the transition theory and summing up all direct and indirect effects.

$$
T=X+X^{2}+X^{3}+\cdots+X^{h}=X(I-X)^{-1} \text {, when } h \rightarrow \infty
$$


where $I$ denote the identity matrix.

Step 5: Obtaining the influence relation map (IRM)

At this step, vectors $R$ and $C$ are achieved by summing up the rows and columns of total relation matrix $T$.

$$
\begin{aligned}
& R=\left[r_{i}\right]_{n \times 1}=\left(\sum_{j=1}^{n} t_{i j}\right)_{\substack{n \times 1 \\
T}} \\
& C=\left[c_{j}\right]_{1 \times n}=\left(\sum_{i=1}^{n} t_{i j}\right)_{1 \times n}
\end{aligned}
$$

where $r_{i}$ is the sum of the $i$ th row of matrix $T$ and represents all the direct and indirect effects which are dispatched from the determinant $F_{i}$ to other determinants. Likewise, $c_{j}$ is the sum of the $j$ th column of matrix $T$ and represents all the direct and indirect effects that the determinant $F_{j}$ receives from the other determinants.

The roles played by the factors in the system are illustrated by a diagram with the horizontal axis $(R+C)$ and the vertical axis $(R-C)$. The degree of the central role (importance) played by the factor $i$ in a system is represented by $\left(r_{i}+c_{i}\right)$, where $\left(r_{i}-c_{i}\right)$ stands for the net effect (i.e. the degree of importance) of the factor $i$ contributed to the system. The factors are categorized into two groups of cause (driver) and effect (receiver) factors. If the value of $\left(r_{i}-c_{i}\right)$ is positive the factor $F_{i}$ is grouped under the category of driver factors which has an influence on other factors; if the value of $\left(r_{i}-c_{i}\right)$ is negative the factor $F_{j}$ is grouped under the category of receiver factors which receives influence from other factors.

Finally, the IRM diagram, which provides valuable insights for decision-making, can be obtained by dataset mapping $(R+C, R-C)$. To refine insignificant effects, decision-makers should define a threshold value for the influence values. The IRM diagram becomes too complicated if the threshold value is too low, and if the value is too high many predictors remain independent without showing their relationship with other predictors. The predictors with influence levels higher than the threshold value in the matrix $T$ are chosen to construct the IRM diagram.

\subsection{Sample and data collection}

Data were collected from 35 individuals including researchers and psychotherapists who were familiar with the issues of Internet and social media addiction and were identified and selected according to their research and job profiles. In order to collect the required data, an appropriate questionnaire was developed fitting the requirements of the DEMATEL method. After validating the content of the developed questionnaire by three DEMATEL experts, the developed questionnaire together with a cover letter introducing the purpose of the study were emailed to the target respondents. They were asked to determine the degree to which a predictor influence (or is influenced by) other predictors. Figure 2 depicts a sample of the designed DEMATEL questionnaire.

Figure 2 shows that if FOMO has a strong direct influence on life satisfaction, as the predictors of social media addiction, then the score " 3 " is assigned to the related cell in the 


\begin{tabular}{|c|c|c|c|c|c|}
\hline & Life satisfaction & Loneliness & Self-esteem & FoMo & Empathy \\
\hline Life satisfaction & $\uparrow$ & & & & 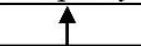 \\
\hline Loneliness & & & & & \\
\hline Self-esteem - & $\uparrow$ & & & & $\rightarrow 2$ \\
\hline FoMo $\quad \longrightarrow$ & $\longrightarrow 3$ & & & & \\
\hline Empathy & & & & & \\
\hline
\end{tabular}

Notes: 0: no influence; 1 : weak direct influence; 2 : moderate direct influence; 3 : strong direct influence; 4: very strong direct influence

Figure 2: Example of the DEMATEL questionnaire

Table 2: Respondents' profile

\begin{tabular}{lll}
\hline Gender & Frequency & Percent $(\%)$ \\
Male & 14 & 40 \\
Female & 21 & 60 \\
Expertise & 29 & 83 \\
Researcher & 6 & 17 \\
$\begin{array}{l}\text { Psychotherapist } \\
\text { Experience (year) }\end{array}$ & & \\
Less than 3 & 4 & 11 \\
3-5 & 23 & 66 \\
More than 5 & 8 & 23 \\
\hline
\end{tabular}

Table 3: Reliability assessment of the DEMATEL questionnaires

\begin{tabular}{lcl}
\hline Test & Cronbach's $\alpha(>0.7)$ & Result \\
\hline Dimensions' questionnaire & 0.877 & Reliable \\
Psychosocial factors questionnaire & 0.901 & Reliable \\
Comorbid symptoms questionnaire & 0.922 & Reliable \\
Personality factors questionnaire & 0.898 & Reliable \\
\hline
\end{tabular}

questionnaire. Conversely, if self-esteem moderately influences empathy, then the score "2" is given to represent this moderate direct relationship.

From the 35 respondents who participated in the current study, six (17 percent) were Internet and social media addiction therapists, and 29 (83 percent) were researchers in the fields ofInternet addiction and social media addiction. Table 2 exhibits the profiles of respondents. To assess the reliability of the collected data, the Cronbach's $\alpha$ criteria were applied and the results revealed that the questionnaire utilized to collect data for the DEMATEL method was reliable. Table 3 exhibits the reliability assessment of the designed questionnaire.

\section{$5 \quad$ Data analysis and results}

In the first stage of the analysis, we used the DEMATEL method following the described approach in Section 4 to find the interdependencies between the predictors of social media addiction. In fact, the DEMATEL technique was used to reveal the cause and effect groups and predictors in the proposed research framework. This stage of identifying the relationships was important as it may help reveal the relative importance of the predictors in each dimension (i.e., psychosocial factors, comorbid symptoms, personality factors).

Utilizing the specifically designed questionnaire (see Figure 2), data were collected and kept in the initial matrices with all dimensions and their indicators. Accordingly, the DEMATEL research method was used, firstly, to determine the level of importance of identified dimensions 
Table 4: Normalized primary direct matrix for psychosocial factors, comorbid symptom, and personality factors

\begin{tabular}{llll}
\hline & Psychosocial factors & Comorbid symptom & Personality factors \\
\hline Psychosocial factors & 0 & 0.46 & 0.49 \\
Comorbid symptom & 0.36 & 0 & 0.51 \\
Personality factors & 0.44 & 0.36 & 0 \\
\hline
\end{tabular}

Table 5: Total relation matrix for the dimensions of psychosocial factors, comorbid symptom, and personality factors

\begin{tabular}{llll}
\hline & Psychosocial factors & Comorbid symptom & Personality factors \\
\hline Psychosocial factors & 2.00 & 2.34 & 2.66 \\
Comorbid symptom & 2.14 & 1.90 & 2.53 \\
Personality factors & 2.08 & 2.06 & 2.07 \\
\hline
\end{tabular}

Table 6: Net causer and net receiver dimensions

\begin{tabular}{lllll}
\hline Factors & $\mathrm{D}$ & $\mathrm{R}$ & $\mathrm{D}+\mathrm{R}$ & $\mathrm{D}-\mathrm{R}$ \\
\hline Psychosocial factors & 7.00 & 6.22 & 13.22 & 0.78 \\
Comorbid symptom & 6.57 & 6.30 & 12.87 & 0.27 \\
Personality factors & 6.21 & 7.30 & 13.51 & -1.09 \\
\hline
\end{tabular}

(i.e., psychosocial, comorbid symptoms, and personality factors), then, to prioritize the predictors of each dimension according to their level of importance level explaining social media addiction.

As described in Section 4 (steps 1 and 2), the average of the responses was calculated to form the initial average matrix $Z=\left[Z_{i j}\right]_{n \times n}$. Subsequently, the normalized primary direct matrix $X=\left[x_{i j}\right]_{n \times n}$ was calculated (see Section 4 , step 3). Table 4 presents the normalized direct matrix for the dimensions of psychosocial factors, comorbid symptoms, and personality factors.

Following the steps 4 and 5 described above (see Section 4), by calculating the normalized primary direct matrix, the total relation matrix $T=\left[t_{i j}\right]_{n \times n}$ was obtained, which can provide the influence rate of each dimension (see Table 5). In addition, the DEMATEL method also identified the relative importance of the factors by calculating the vectors $R$ and $C$ (see Table 6). This table reveals that psychosocial factors and comorbid symptom are net causer dimensions $(D-R>0)$ and the dimension of personality factors is a net receiver $(D-R<0)$. Furthermore, the results revealed that, with respect to social media addiction, the most important dimension is the personality factors dimension $(R+D=13.47)$ followed by the dimensions of psychosocial factors and comorbid symptom.

To define the threshold value we applied the approach suggested by Tamura et al. (2002) and use the value of 2.197 which is the average value of the elements of matrix $T$. Considering the defined threshold value, the significant relationships are depicted in Figure 3. The results clearly show that the dimension of psychosocial factors has significantly influenced the dimensions of comorbid symptoms and personality factors. In addition, it can be seen that the dimension of personality factors has received significant impacts from the dimensions of psychosocial factors and comorbid symptoms.

This procedure is also applied to the predictors of each dimension. The DEMATEL technique was applied to find the cause and effect factors and their relative importance according 


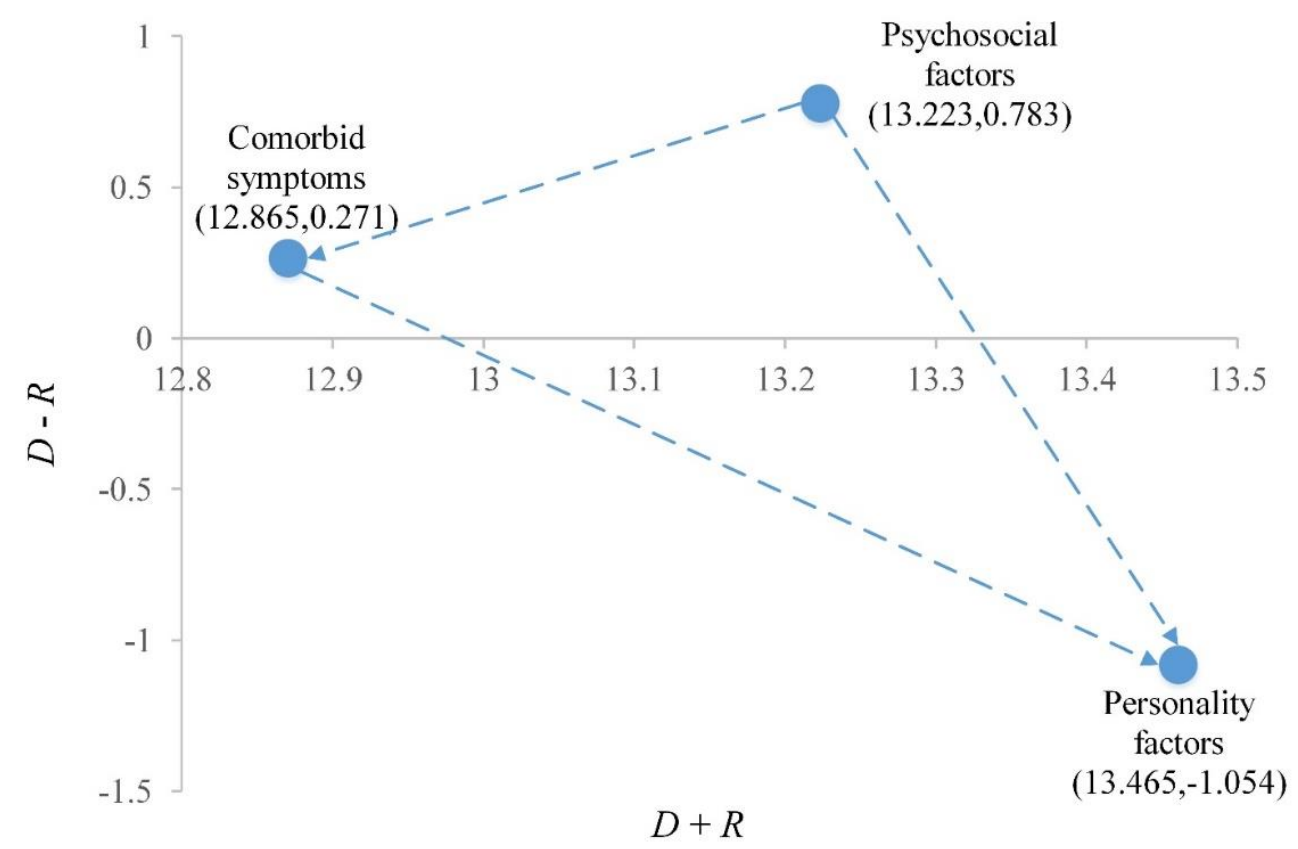

Figure 3: IRM diagram of the dimensions of psychosocial factors, comorbid symptom and personality factors with respect to social media addiction

Table 7: Net causer and net receiver factors in psychosocial factors, comorbid symptom, and personality dimensions

\begin{tabular}{llllll}
\hline Dimensions & Indicators & D & R & D+R & D-R \\
\hline Psychosocial factors & FoMo & 2.18 & 2.07 & 4.25 & 0.11 \\
& Loneliness & 3.05 & 2.15 & 5.20 & 0.90 \\
& Self-esteem & 2.60 & 2.35 & 4.94 & 0.25 \\
& Empathy & 1.54 & 2.42 & 3.96 & -0.88 \\
& Life Satisfaction & 1.85 & 2.23 & 4.08 & -0.38 \\
Comorbid symptoms & ADHD & 2.12 & 2.20 & 4.32 & -0.07 \\
& Depression & 3.05 & 2.03 & 5.08 & 1.02 \\
& Compulsivity & 1.27 & 2.90 & 4.17 & -1.63 \\
& Impulsivity & 2.78 & 2.10 & 4.88 & 0.68 \\
& Agreeableness & 0.45 & 0.36 & 0.81 & 0.09 \\
& Conscientiousness & 0.19 & 0.46 & 0.65 & -0.26 \\
& Neuroticism & 0.43 & 0.41 & 0.84 & 0.02 \\
& Openness to experience & 0.63 & 0.36 & 0.99 & 0.28
\end{tabular}

to the respondents' accounts. The results are presented in Table 7 which show that loneliness, openness to experience and depression are the most important predictors across the psychosocial, personality and comorbid symptom dimensions, respectively. The results further reveal that life satisfaction, empathy, compulsivity, conscientiousness, and extraversion are net receiver factors with negative values for $D-R$, and FoMo, loneliness, self-esteem, depression, impulsivity, narcissism, neuroticism and agreeableness are net causer factors, indicating these factors have a significant impact on the other factors for social media addiction. 


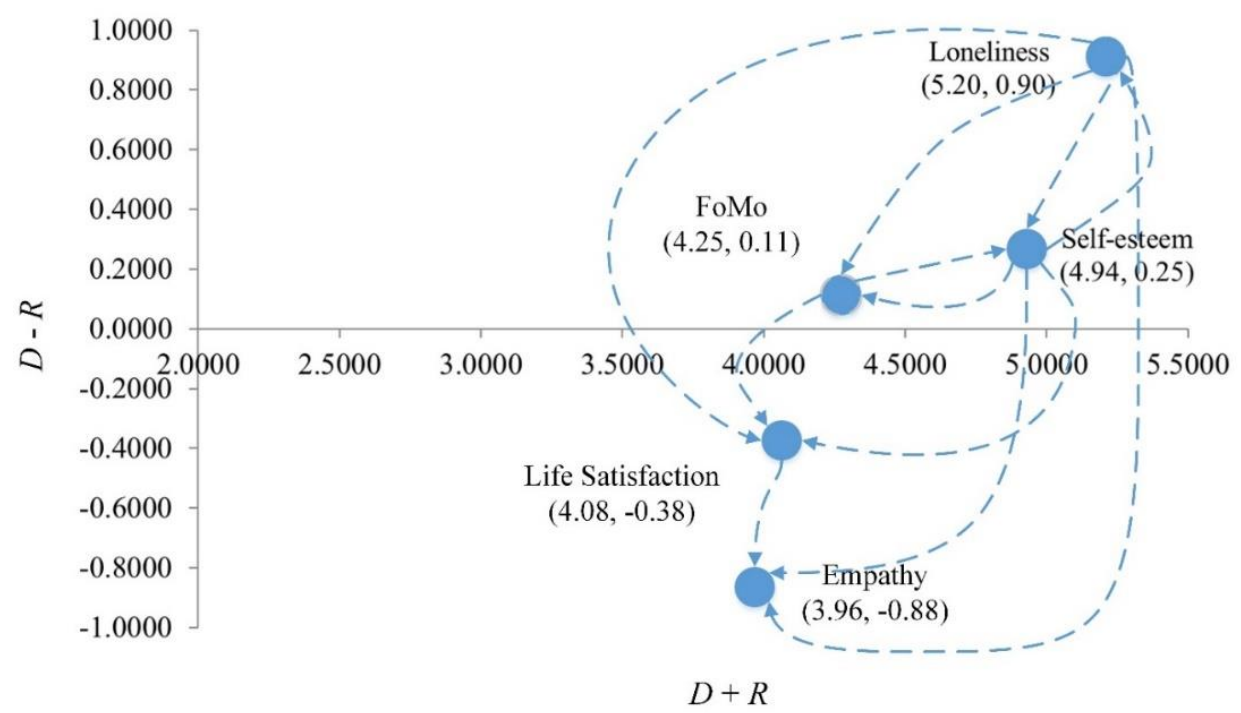

(a) Psychosocial factors

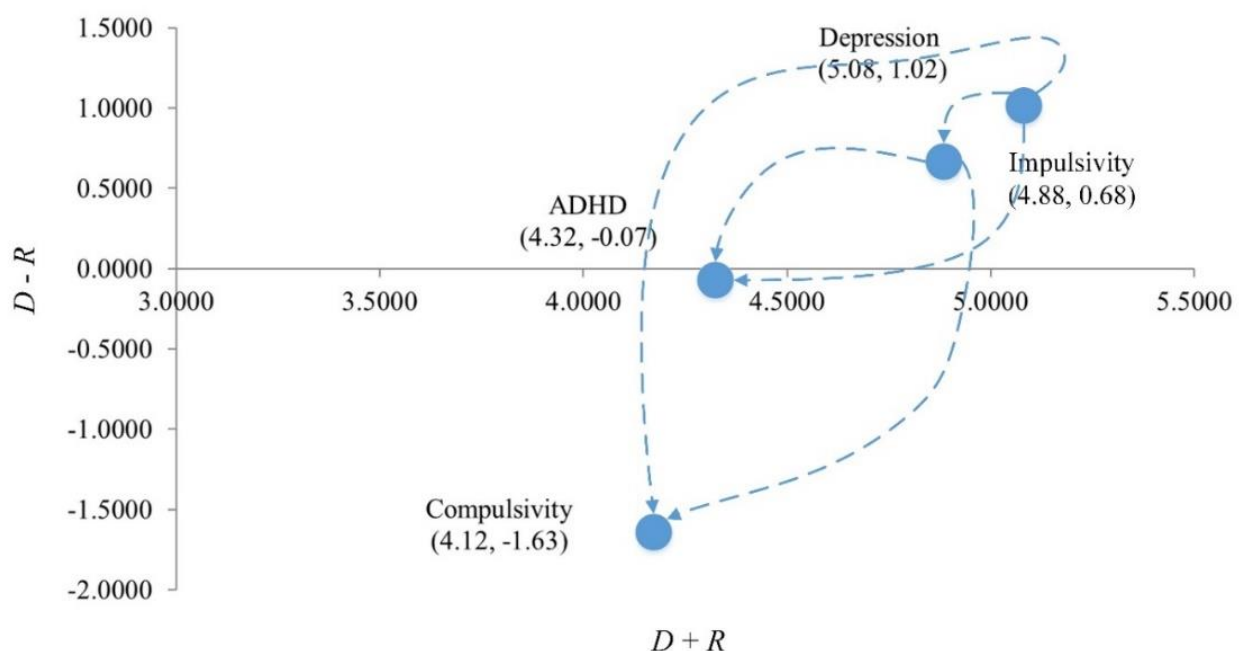

(b) Comorbid symptom

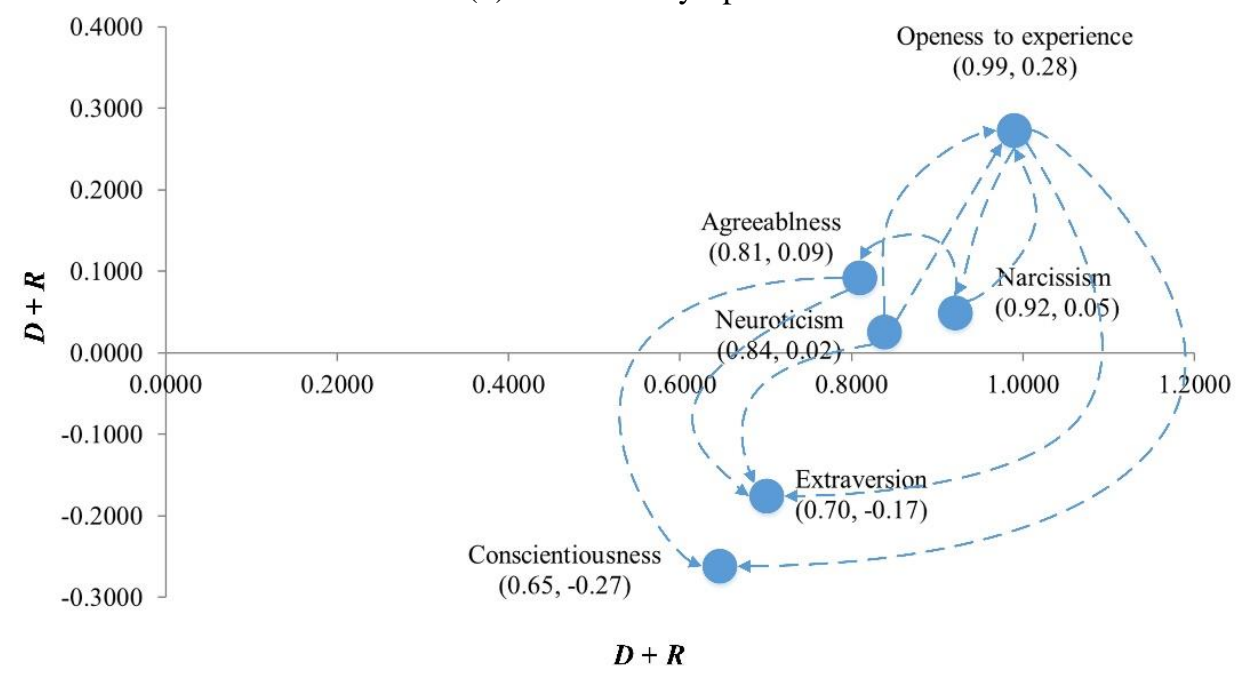

(c) Personality factors

Figure 4: The significant relationships between the predictors of social media addiction 


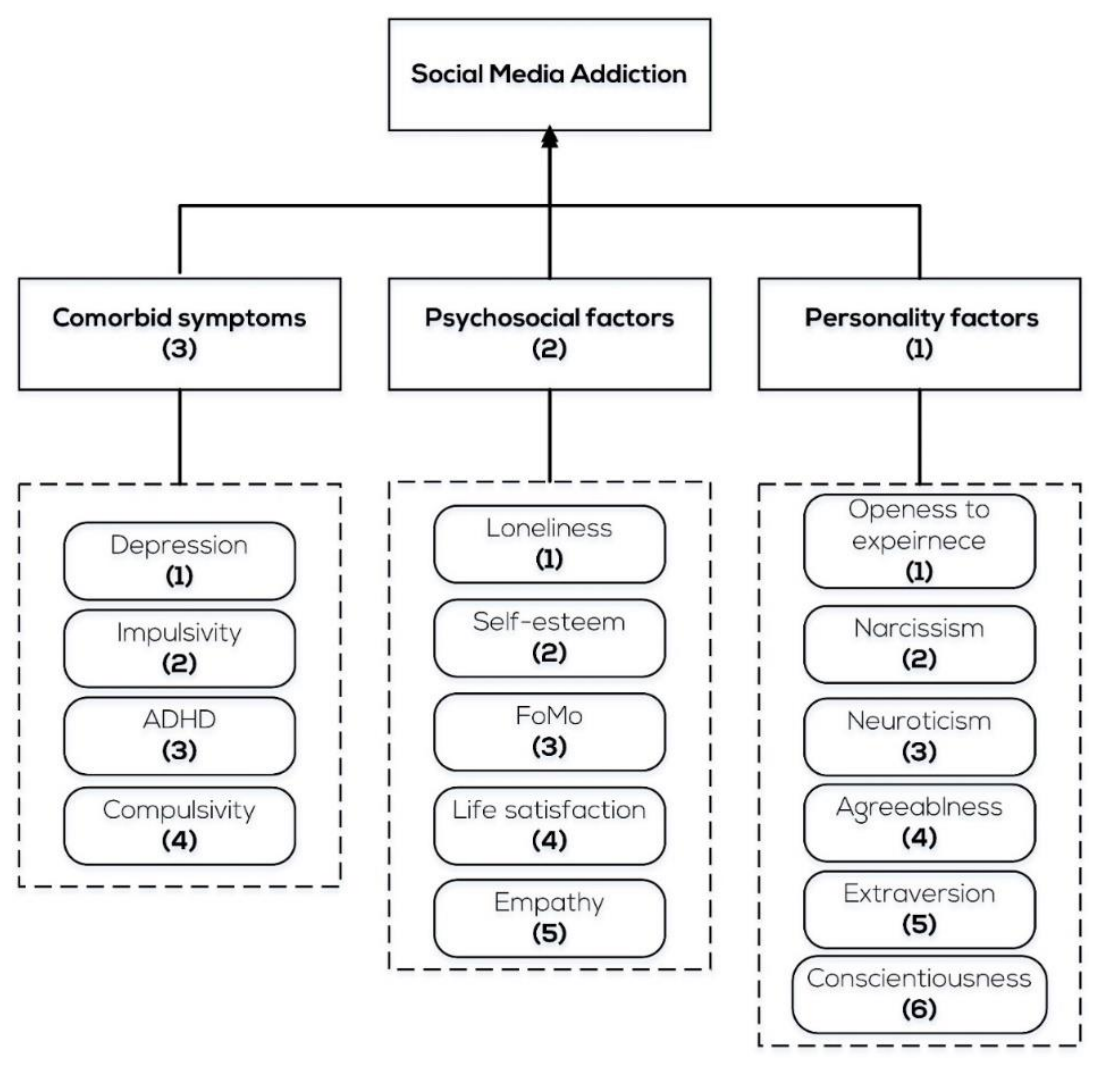

Figure 5: Rankings according to the DEMATEL results

The significant relationships are presented in Figure 4. From the plots in Figure 4, the influence of specific factors on the others can be better understood. For example, as seen in Figure $4 \mathrm{a}$, loneliness has influenced all other factors in the psychosocial dimension, which means psychosocial interventions for social media addiction should focus more on the loneliness which was recognized as the net cause predictor among the other predictors in the psychosocial factors dimension. In addition, from Figure $4 \mathrm{~b}$, it can be seen that compulsivity was impacted by depression and impulsivity factors. It means that to decrease compulsivity, interventions should focus on alleviating depression and impulsivity symptoms of social media addicts. The results in Figure $4 \mathrm{c}$ also reveal that conscientiousness and extraversion were impacted by the other factors, indicating that there were no impacts from these factors on agreeableness, neuroticism, openness to experience and narcissism.

According to the results provided above, it is concluded that from the three dimensions, personality factors are recognized as the most important dimension in explaining adolescents' social media addiction from the respondents' perspective. From the personality factors, the respondents identified traits of openness to experience and narcissism as the two most important ones predicting social media addiction. For psychosocial factors, as the second important dimension, the predictors loneliness and self-esteem were highlighted as the two most important ones. Finally, depression and impulsivity, as the determinants grouped under comorbid symptoms, were expressed as the first two important predictors. Figure 5 illustrates the final ranking of dimensions and related predictors of social media addiction based on the respondents' perspective. 


\section{Discussion and conclusion}

The present study aimed to provide psychotherapists' and researchers' perspectives on the predictors of social media addiction based on the established research evidence. The impact of related constructs, including the fear of missing out, compulsive use, self-esteem, attention deficit disorder, impulsivity, loneliness, personality traits, narcissism, life satisfaction, depression and empathy were considered by 35 individuals familiar with the field, most of whom have professional experience of working with social media addiction in research and clinical contexts for more than three years. Based on a previously established framework (Kuss et al., 2014), predictors were grouped into psychosocial factors, comorbid symptoms, and personality factors. To reveal the repondents' points of views, the DEMATEL method approach has been applied. The utilization of the DEMATEL method in the context of social media addiction has a number of advantages such as (1) analyzing the mutual influences between the predictors of social media addiction (both direct and indirect relationships) and understanding the cause and effect correlations in decision-making problems; (2) the ability to visualize the interrelationships between the predictors through the IRM diagram to assist decision-makers to further understand which predictors are impacting one another; and (3) the DEMATEL method helps not only to rank the predictors of social media addiction according to their level of importance, but also to identify the most critical dimensions and predictors of social media addiction.

In a recent study, Brand et al. (2016) developed an integrated model of Internet-related addictions and disorders called "Interaction of Person-Affect-Cognition-Execution (I-PACE)". The purpose of I-PACE model was to reveal that the addiction to a specific type of Internet application or site could be explained with one's core characteristics, predisposing factors, and some moderator or mediator variables (Kircaburun and Griffiths, 2018). For personality traits, the I-PACE model asserted that while consistent correlations among some personality traits and addiction has been found in the literature (e.g., Błachnio et al., 2017; Kircaburun et al., 2018; Kircaburun and Griffiths, 2018; Singh et al., 2018), it is important to investigate such correlation and relationship for a specific type of Internet application. Consistent with the results of previous studies and following the recommendation of the I-PACE model, the current study investigated the importance of the correlation between personality traits and addiction in the context of social media.

The results indicate that personality factors were the strongest predictors across the three dimensions, especially openness to experience and narcissism. Openness to experience has previously been found to be associated with online gaming addiction in university students (Kuss et al., 2013a), indicating the more open to experience participants were and the more time they spent engaged in online gaming, the higher their addiction scores were. Recent research on social media usage supported the link with openness to experience for women only (Correa et al., 2010). Given social media are a relatively new application and women engage with it more frequently and possibly more problematically than men (Kanjo et al., 2017), this result is not surprising. Females use social media for its social functions and to stay connected, which is a different usage motivation in comparison to that of males, who tend to play online games for competition and reward-related motivations, which is similarly evident in the clinical context (Kuss and Griffiths, 2015).

In terms of narcissism, previous research has indicated that individuals who score higher on narcissism scales appear to have a more pronounced presence on social media sites, and are 
more likely to post selfies and engage in other activities on social media in order to gain interest and admiration from friends and followers on these websites, which has been linked to "grandiose exhibitionism" (Singh et al., 2018). It appears narcissistic individuals use social media in order to satisfy their needs for recognition and esteem, which, if used to excess, may be predictive of compulsive and addictive use.

The results of the study also showed that the trait of neuroticism received great attention from the respondents participated in the current study. Neuroticism found to be positively related to problematic social media use (e.g., Blackwell et al., 2017; Lachmann et al., 2018; Tang et al., 2016). Individuals with a high degree of neuroticism are more intend to use social media applications and sites such as Instagram or Facebook to further receive "[...] feedback and reassurance from others" (Blackwell et al., 2017), or maybe they prefer such medium to communicate rather than the face-to-face one. In the study by Blackwell et al. (2017), the authors reported the mediated relationship between neuroticism and social media addiction, in that, the effect of neuroticism was stronger once mediated through the insecure attachment style.

For the psychosocial factors, as the second important dimension predicting social media addiction in the current study, the predictor's loneliness, self-esteem, and FOMO were highlighted as most important. Although increasing connection and the potential to interact via the online platforms, social media interactions miss the inherent ingredient of face-to-face interaction, namely that of limbic resonance (Lewis et al., 2001), in essence, the idea of why I feel what you feel. Without the possibility to observe a conversation partner, there is no possibility of picking up on non-verbal cues transmitted via body language and facial expression, limiting the amount of social context cues (Sproull and Kiesler, 1986) and social presence (Rice and Love, 1987), with the possible consequence of loneliness despite connection.

Limited self-esteem, on the other hand, has previously been associated with the use of the photo-sharing site Instagram (Tiggemann and Zaccardo, 2015) due to increased social comparison and self-objectification (Ward et al., 2018). This can lead to body image dissatisfaction and physical appearance anxiety (Sherlock and Wagstaff, 2018), and may contribute to feelings of depression (Donnelly and Kuss, 2016). The comparisons made on social media platforms such as Instagram are often unfavorable for the user, as many individuals with large numbers of followers (i.e., celebrities) tend to lead more luxurious and adventurous lives, to which the average user's life pales in comparison, with the effect of decreased self-esteem.

FOMO, the need to feel constantly connected online, has been coined recently (Przybylski et al., 2013), and has been found to be a strong driver for social media use in previous research (Kuss and Griffiths, 2017). Recent research (Pontes et al., 2018)indicates that FOMO, alongside irrational beliefs and poor mental health, is a strong predictor of social media addiction. Given that nowadays smartphone notifications serve as constant reminders of what is going on in our social media feeds (Kanjo et al., 2017), FOMO can be driven, and result in addictive use.

Finally, depression, as one of the determinants grouped under comorbid symptoms, appeared as the most important predictor of social media addiction within this dimension in the present study. This replicates previous studies' findings that have indicated depression was strongly associated with social media use in a large sample of US young adults (Lin et al., 2016) as well as a sample of Scottish adolescents (Woods and Scott, 2016), in which emotional investment contributed to the results. It appears that the extent to which users are invested in their social media accounts and the connections they have on those websites may be a contributing factor to feeling low and experiencing symptoms of depression. 


\section{Contributions}

Implications of the current study are for both theory and practice. Altogether, the present study contributes to a growing body of knowledge within the field of excessive and addictive social media use and paves the way for additional research that may replicate and extend the findings by adding a qualitative element, which will allow experts to provide more detail on their professional experience with working with social media addiction, including risk and protective factors. In addition to this, research (Donnelly and Kuss, 2016) has previously pointed to the requirement of needing to distinguish between the use of different social media platforms, as the use of some was found to be associated with higher levels of depression and addiction symptoms; i.e., the excessive use of the video-sharing site Instagram appears as a more severe problem in comparison to other sites, such as Facebook, Twitter, and Snapchat.

Practically, the results of the study can help psychotherapists to prioritize their intervention plans and programs according to the reported importance of the predictors. Young (2013) developed a three-phase treatment model of Internet addiction called Cognitive Behavioral Therapy - Internet Addiction (CBT-IA). The results of the present study can be applied in the second phase of the CBT-IA, which focuses on recognizing and addressing maladaptive cognitions. During the treatment phase, a therapist can prioritize recognition approach according to the order of the predictors of social media addiction and further apply related interventions. In another study Young and Brand (2017)combined the CBT-IA therapy model and the I-PACE theoretical model to further guide experts through treatment of specific Internet addiction. Since the current study investigated more distal predictors of social media addiction, the retrieved results can be applied in first box of the proposed model that is person's core characteristics. To apply the harm reduction phase of CBT-IA to this section, psychotherapists can adjust their recognition and treatment programs in accordance with the importance level of predictors reported in this study.

\section{Conclusion}

Social media addiction is an unwelcome yet growing problem especially for young users of these kinds of websites. National reports (Griffiths et al., 2018) indicate the need for more government-sponsored research as well as the need for shared responsibility on behalf of parents, educators, researchers, practitioners and the social media providers in terms of safeguarding users. Collaborative work is required to make social media a safe space to be enjoyed by all users. Although novel and insightful in its approach, the DEMATEL approach applied in the present study had a small number of limitations. This study relied on respondents' own views and experience with working with social media addiction, inevitably integrating a subjective element within the research. In addition to this, some of the researchers and clinicians involved in the study as participants have had less than three years' experience working with this problematic online behavior, which may have impacted knowledge and understanding of the problem at hand. Future replications of the study should ensure that breadth and depth of knowledge of and experience with social media addiction are confirmed through the length of experience, and professional qualifications. Future research will also benefit from the accounts of users who experience addiction-related symptoms as a consequence of their social media use, including the associated personality, comorbid and psychosocial factors, and the DEMATEL approach should be applied within this group. 


\section{References}

Andreassen, C. S., and Pallesen, S. (2014). Social network site addiction-an overview. Current Pharmaceutical Design, 20(25), 4053-4061.

Andreassen, C. S., Pallesen, S., and Griffiths, M. D. (2016). The relationship between addictive use of social media, narcissism, and self-esteem: Findings from a large national survey. Addictive behaviors.

Balakrishnan, V., and Shamim, A. (2013). Malaysian Facebookers: Motives and addictive behaviours unraveled. Computers in Human Behavior, 29(4), 1342-1349.

Błachnio, A., and Przepiorka, A. (2016). Personality and positive orientation in Internet and Facebook addiction. An empirical report from Poland. Computers in Human Behavior, 59, 230-236.

Błachnio, A., and Przepiórka, A. (2018). Facebook intrusion, fear of missing out, narcissism, and life satisfaction: A cross-sectional study. Psychiatry research, 259, 514-519.

Błachnio, A., Przepiorka, A., Boruch, W., and Bałakier, E. (2016a). Self-presentation styles, privacy, and loneliness as predictors of Facebook use in young people. Personality and Individual Differences, 94, 26-31.

Błachnio, A., Przepiorka, A., and Pantic, I. (2016b). Association between Facebook addiction, self-esteem and life satisfaction: A cross-sectional study. Computers in human behavior, 55, 701-705.

Błachnio, A., Przepiórka, A., and Pantic, I. (2015). Internet use, Facebook intrusion, and depression: Results of a cross-sectional study. European Psychiatry, 30(6), 681-684.

Błachnio, A., Przepiorka, A., Senol-Durak, E., Durak, M., and Sherstyuk, L. (2017). The role of personality traits in Facebook and Internet addictions: A study on Polish, Turkish, and Ukrainian samples. Computers in Human Behavior, 68, 269-275.

Blackwell, D., Leaman, C., Tramposch, R., Osborne, C., and Liss, M. (2017). Extraversion, neuroticism, attachment style and fear of missing out as predictors of social media use and addiction. Personality and Individual Differences, 116, 69-72.

Brand, M., Young, K. S., and Laier, C. (2014). Prefrontal control and internet addiction: a theoretical model and review of neuropsychological and neuroimaging findings. Front Hum Neurosci, 8, 375.

Brand, M., Young, K. S., Laier, C., Wölfling, K., and Potenza, M. N. (2016). Integrating psychological and neurobiological considerations regarding the development and maintenance of specific Internet-use disorders: An Interaction of Person-Affect-CognitionExecution (I-PACE) model. Neuroscience Biobehavioral Reviews, 71, 252-266.

Chóliz, M., Marcos, M., and Lázaro-Mateo, J. (2019). The Risk of Online Gambling: a Study of Gambling Disorder Prevalence Rates in Spain. International Journal of Mental Health and Addiction.

Correa, T., Hinsley, A. W., and de Zúñiga, H. G. (2010). Who interacts on the Web?: The intersection of users' personality and social media use. Computers in Human Behavior, 26(2), 247-253.

Davis, R. A. (2001). A cognitive-behavioral model of pathological Internet use. Computers in Human Behavior, 17(2), 187-195.

de Alarcón, R., de la Iglesia, J. I., Casado, N. M., and Montejo, A. L. (2019). Online Porn Addiction: What We Know and What We Don't-A Systematic Review. Journal of clinical medicine, 8(1), 91.

Dhir, A., Kaur, P., Lonka, K., and Tsai, C.-C. (2017). Do psychosocial attributes of well-being drive intensive Facebook use? Computers in Human Behavior, 68, 520-527. 
Dhir, A., Yossatorn, Y., Kaur, P., and Chen, S. (2018). Online social media fatigue and psychological wellbeing-A study of compulsive use, fear of missing out, fatigue, anxiety and depression. International Journal of Information Management, 40, 141-152.

Donnelly, E., and Kuss, D. (2016). Depression among users of social networking sites (SNSs): The role of SNS addiction and increased usage. Journal of Addiction and Preventive Medicine, 1(2), 107.

Duval, A., Fontela, E., and Gabus, A. (1974). DEMATEL Report. In Cross-Impact: A Handbook on Concepts and Applications Innovative Methods: Batelle Geneva Research Center.

Fraumeni-McBride, J. (2019). Addiction and mindfulness; pornography addiction and mindfulness-based therapy (ACT). Sexual Addiction \& Compulsivity, 1-12.

Gentile, D. A., Choo, H., Liau, A., Sim, T., Li, D., Fung, D., et al. (2011). Pathological video game use among youths: a two-year longitudinal study. Pediatrics, peds. 2010-1353.

Goldberg, I. (1996). Internet addiction disorder.

Grammenos, P., Syrengela, N., Magkos, E., and Tsohou, A. (2017). Internet Addiction of Young Greek Adults: Psychological Aspects and Information Privacy. In GeNeDis 2016 (pp. 6778): Springer.

Griffiths, M. (2000). Does Internet and computer" addiction" exist? Some case study evidence. CyberPsychology and Behavior, 3(2), 211-218.

Griffiths, M. (2005). A 'components' model of addiction within a biopsychosocial framework. Journal of Substance Use, 10(4), 191-197.

Griffiths, M., Lopez-Fernandez, O., Throuvala, M., Pontes, H. M., and Kuss, D. J. (2018). Excessive and problematic use of social media in adolescence: A brief overview. Report submitted to the UK Parliament Science and Technology Committee (Impact of social media and screen-use on young people's health inquiry). Nottingham: Nottingham Trent Universityo. Document Number)

Gruzd, A., Haythornthwaite, C., Paulin, D., Gilbert, S., and del Valle, M. E. (2016). Uses and Gratifications factors for social media use in teaching: Instructors' perspectives. new media \& society, 1461444816662933.

Ha, J. H., Yoo, H. J., Cho, I. H., Chin, B., Shin, D., and Kim, J. H. (2006). Psychiatric comorbidity assessed in Korean children and adolescents who screen positive for Internet addiction. The Journal of clinical psychiatry.

Hardie, E., and Tee, M. Y. (2007). Excessive Internet use: the role of personality, loneliness and social support networks in Internet addiction. Australian Journal of Emerging Technologies \& Society, 5(1).

Hong, F.-Y., Huang, D.-H., Lin, H.-Y., and Chiu, S.-L. (2014). Analysis of the psychological traits, Facebook usage, and Facebook addiction model of Taiwanese university students. Telematics and Informatics, 31(4), 597-606.

Hong, F. Y., and Chiu, S. L. (2014). Factors influencing Facebook usage and Facebook addictive tendency in university students: The role of online psychological privacy and Facebook usage motivation. Stress and Health, 32, 117-126.

Hussain, Z., Williams, G. A., and Griffiths, M. D. (2015). An exploratory study of the association between online gaming addiction and enjoyment motivations for playing massively multiplayer online role-playing games. Computers in Human Behavior, 50, 221-230.

Jeong, H., Lee, Y. J. A. S., and Letters, T. (2015). Smartphone addiction and empathy among nursing students. 88, 224-228.

Jia, J., Li, D., Li, X., Zhou, Y., Wang, Y., and Sun, W. (2017). Psychological security and deviant peer affiliation as mediators between teacher-student relationship and adolescent Internet addiction. Computers in Human Behavior, 73, 345-352. 
Jiang, Q., Huang, X., and Tao, R. (2017). Examining Factors Influencing Internet Addiction and Adolescent Risk Behaviors Among Excessive Internet Users. Health Communication, 111.

Jiaojiao, J., Chuang, G., and Gengfeng, N. (2017). The effect of internet use on empathy. 25(4), 652-661.

Jun, S., and Choi, E. (2015). Academic stress and Internet addiction from general strain theory framework. Comput. Hum. Behav., 49(C), 282-287.

Kanjo, E., Kuss, D. J., and Ang, C. S. (2017). NotiMind: Utilizing Responses to Smart Phone Notifications as Affective sensors. IEEE Access, 5, 22023-22035.

Kayiş, A. R., Satici, S. A., Yilmaz, M. F., Şimşek, D., Ceyhan, E., and Bakioğlu, F. (2016). Big five-personality trait and internet addiction: A meta-analytic review. Computers in Human Behavior, 63, 35-40.

Kircaburun, K., Alhabash, S., Tosuntaş, Ş. B., and Griffiths, M. D. (2018). Uses and Gratifications of Problematic Social Media Use Among University Students: a Simultaneous Examination of the Big Five of Personality Traits, Social Media Platforms, and Social Media Use Motives. International Journal of Mental Health and Addiction, 1-23.

Kircaburun, K., and Griffiths, M. D. (2018). Instagram addiction and the Big Five of personality: The mediating role of self-liking. Journal of behavioral addictions, 7(1), 158-170.

Kircaburun, K., and Griffiths, M. D. (2018). Problematic Instagram use: The role of perceived feeling of presence and escapism. International Journal of Mental Health and Addiction, $1-13$

Koc, M., and Gulyagci, S. (2013). Facebook addiction among Turkish college students: The role of psychological health, demographic, and usage characteristics. Cyberpsychology, Behavior, and Social Networking, 16(4), 279-284.

Kuss, D. (2017). Mobile Technology and Social Media: The "Extensions of Man" in the 21st Century. Human Development, 60(4), 141-143.

Kuss, D., D Griffiths, M., Karila, L., and Billieux, J. (2014). Internet addiction: a systematic review of epidemiological research for the last decade. Current pharmaceutical design, 20(25), 4026-4052.

Kuss, D., and Griffiths, M. (2011). Addiction to social networks on the internet: A literature review of empirical research. International Journal of Environment and Public Health, 8(9), 35283552.

Kuss, D., and Griffiths, M. D. (2015). Internet Addiction in Psychotherapy. Basingstoke: Palgrave Macmillan.

Kuss, D. J., and Griffiths, M. D. (2017). Social networking sites and addiction: Ten lessons learned. International journal of environmental research and public health, 14(3), 311.

Kuss, D. J., Griffiths, M. D., and Binder, J. F. J. C. i. H. B. (2013a). Internet addiction in students: Prevalence and risk factors. 29(3), 959-966.

Kuss, D. J., Van Rooij, A. J., Shorter, G. W., Griffiths, M. D., and van de Mheen, D. (2013b). Internet addiction in adolescents: Prevalence and risk factors. Computers in Human Behavior, 29(5), 1987-1996.

Lachmann, B., Sindermann, C., Sariyska, R. Y., Luo, R., Melchers, M. C., Becker, B., et al. (2018). The Role of Empathy and Life Satisfaction in Internet and Smartphone Use Disorder. Frontiers in Psychology, 9(398).

Lam, L. T., Peng, Z.-w., Mai, J.-c., and Jing, J. (2009). Factors associated with Internet addiction among adolescents. CyberPsychology \& Behavior, 12(5), 551-555.

Lemmens, J. S., Valkenburg, P. M., and Gentile, D. A. (2015). The Internet gaming disorder scale. Psychological assessment, 27(2), 567. 
Lewis, T., Amini, F., and Lannon, R. (2001). A general theory of love. New York, NY: Vintage.

Lin, L. Y., Sidani, J. E., Shensa, A., Radovic, A., Miller, E., Colditz, J. B., et al. (2016). Association between social media use and depression among US young adults. Depression anxiety, 33(4), 323-331.

Lin, Y., Lin, Y., Lin, S., Lee, Y., Lin, P., Chiang, C., et al. (2017). To use or not to use? Compulsive behavior and its role in smartphone addiction. Translational psychiatry, 7(2), e1030.

Liu, C., and Ma, J. (2018). Development and validation of the Chinese social media addiction scale. Personality and Individual Differences, 134, 55-59.

Longstreet, P., and Brooks, S. (2017). Life satisfaction: A key to managing internet \& social media addiction. Technology in Society, 50, 73-77.

Mitchell, P. (2000). Internet addiction: genuine diagnosis or not? The Lancet, 355(9204), 632.

Nie, J., Zhang, W., and Liu, Y. (2017). Exploring depression, self-esteem and verbal fluency with different degrees of internet addiction among Chinese college students. Comprehensive Psychiatry, 72, 114-120.

Oberst, U., Wegmann, E., Stodt, B., Brand, M., and Chamarro, A. (2017). Negative consequences from heavy social networking in adolescents: The mediating role of fear of missing out. Journal of adolescence, 55, 51-60.

Pantic, I., Milanovic, A., Loboda, B., Błachnio, A., Przepiorka, A., Nesic, D., et al. (2017). Association between physiological oscillations in self-esteem, narcissism and internet addiction: A cross-sectional study. Psychiatry Research.

Pontes, H. M., Taylor, M., and Stavropoulos, V. (2018). Beyond "Facebook Addiction": The Role of Cognitive-Related Factors and Psychiatric Distress in Social Networking Site Addiction. yberpsychology, Behavior, Social Networking, 21(4), 240-247.

Przybylski, A. K., Murayama, K., DeHaan, C. R., and Gladwell, V. (2013). Motivational, emotional, and behavioral correlates of fear of missing out. Computers in Human Behavior, 29(4), 1841-1848.

Quan-Haase, A., and Young, A. L. (2010). Uses and gratifications of social media: A comparison of Facebook and instant messaging. Bulletin of Science, Technology \& Society, 30(5), 350361.

Rice, R. E., and Love, G. (1987). Electronic emotion: Socioemotional content in a computermediated communication network. Communication research, 14(1), 85-108.

Ryan, T., Chester, A., Reece, J., and Xenos, S. (2014). The uses and abuses of Facebook: A review of Facebook addiction. Journal of Behavioral Addictions, 3, 133-148.

Sariyska, R., Reuter, M., Bey, K., Sha, P., Li, M., Chen, Y.-F., et al. (2014). Self-esteem, personality and internet addiction: a cross-cultural comparison study. Personality and Individual Differences, 61, 28-33.

Satici, S. A., and Uysal, R. (2015). Well-being and problematic Facebook use. Computers in Human Behavior, 49, 185-190.

Shaw, M., and Black, D. W. (2008). Internet addiction: definition, assessment, epidemiology and clinical management. CNS Drugs, 22(5), 353-365.

Shen, Y.-C., Lin, G. T. R., and Tzeng, G.-H. (2011). Combined DEMATEL techniques with novel MCDM for the organic light emitting diode technology selection. Expert Systems with Applications, 38(3), 1468-1481.

Sherlock, M., and Wagstaff, D. L. (2018). Exploring the relationship between frequency of Instagram use, exposure to idealized images, and psychological well-being in women. Psychology of Popular Media Culture.

Singh, S., Farley, S. D., and Donahue, J. J. (2018). Grandiosity on display: Social media behaviors and dimensions of narcissism. Personality Individual Differences, 134, 308-313. 
Sirola, A., Kaakinen, M., Savolainen, I., and Oksanen, A. (2019). Loneliness and online gamblingcommunity participation of young social media users. Computers in Human Behavior, 95, 136-145.

Smock, A. D., Ellison, N. B., Lampe, C., and Wohn, D. Y. (2011). Facebook as a toolkit: A uses and gratification approach to unbundling feature use. Computers in Human Behavior, 27(6), 2322-2329.

Song, I., Larose, R., Eastin, M. S., and Lin, C. A. (2004). Internet gratifications and Internet addiction: On the uses and abuses of new media. CyberPsychology \& Behavior, 7(4), 384394.

Sproull, L., and Kiesler, S. (1986). Reducing social context cues: Electronic mail in organizational communication. Management science, 32(11), 1492-1512.

Sumrit, D., and Anuntavoranich, P. (2013). Using DEMATEL method to analyze the causal relations on technological innovation capability evaluation factors in Thai technologybased firms. Int. Trans. J. Eng., Manage., Appl. Sci. Technol, 4(2), 81-103.

Tamura, M., Nagata, H., and Akazawa, K. (2002). Extraction and systems analysis of factors that prevent safety and security by structural models. Paper presented at the SICE 2002. Proceedings of the 41st SICE Annual Conference, 1752-1759.

Tang, J.-H., Chen, M.-C., Yang, C.-Y., Chung, T.-Y., and Lee, Y.-A. (2016). Personality traits, interpersonal relationships, online social support, and Facebook addiction. Telematics and Informatics, 33(1), 102-108.

Teo, W. J. S., and Lee, C. S. (2016, 7-9 December). Sharing Brings Happiness?: Effects of Sharing in Social Media Among Adult Users. Paper presented at the Digital Libraries: Knowledge, Information, and Data in an Open Access Society, Proceedings of the 18th International Conference on Asia-Pacific Digital Libraries, ICADL 2016, Tsukuba, Japan, 351-365.

Tian, M., Tao, R., Zheng, Y., Zhang, H., Yang, G., Li, Q., et al. (2018). Internet gaming disorder in adolescents is linked to delay discounting but not probability discounting. Computers in Human Behavior, 80, 59-66.

Tiggemann, M., and Zaccardo, M. (2015). "Exercise to be fit, not skinny": The effect of fitspiration imagery on women's body image. Body image, 15, 61-67.

Turel, O., Brevers, D., and Bechara, A. (2018). Time distortion when users at-risk for social media addiction engage in non-social media tasks. Journal of psychiatric research, 97, 84-88.

van den Eijnden, R. J., Lemmens, J. S., and Valkenburg, P. M. (2016). The social media disorder scale. Computers in Human Behavior, 61, 478-487.

Ward, L. M., Seabrook, R. C., Grower, P., Giaccardi, S., and Lippman, J. R. (2018). Sexual Object or Sexual Subject? Media Use, Self-Sexualization, and Sexual Agency Among Undergraduate Women. Psychology of Women Quarterly, 42(1), 29-43.

Wichstrom, L., Stenseng, F., Belsky, J., von Soest, T., and Hygen, B. W. (2019). Symptoms of Internet Gaming Disorder in Youth: Predictors and Comorbidity. J Abnorm Child Psychol, 47(1), 71-83.

Williams, D., and Whiting, A. (2013). Why people use social media: a uses and gratifications approach. Qualitative Market Research: An International Journal, 16(4), 362-369.

Wolniewicz, C. A., Tiamiyu, M. F., Weeks, J. W., and Elhai, J. D. (2018). Problematic smartphone use and relations with negative affect, fear of missing out, and fear of negative and positive evaluation. Psychiatry research, 262, 618-623.

Woods, H. C., and Scott, H. (2016). \#Sleepyteens: Social media use in adolescence is associated with poor sleep quality, anxiety, depression and low self-esteem. Journal of Adolescence, $51,41-49$. 
Wu, A. M., Cheung, V. I., Ku, L., and Hung, E. P. (2013). Psychological risk factors of addiction to social networking sites among Chinese smartphone users. Journal of behavioral addictions, 2(3), 160-166.

Young, K. S. (1996). Psychology of computer use: XL. Addictive use of the Internet: a case that breaks the stereotype. Psychological reports, 79(3), 899-902.

Young, K. S. (1998). Caught in the net: How to recognize the signs of internet addiction--and a winning strategy for recovery: John Wiley \& Sons.

Young, K. S. (2013). Treatment outcomes using CBT-IA with Internet-addicted patients. Journal of behavioral addictions, 2(4), 209-215.

Young, K. S., and Brand, M. (2017). Merging Theoretical Models and Therapy Approaches in the Context of Internet Gaming Disorder: A Personal Perspective. Frontiers in psychology, 8, 1853-1853.

Yu, S., Wu, A. M. S., and Pesigan, I. J. A. (2016). Cognitive and psychosocial health risk factors of social networking addiction. International Journal of Mental Health and Addiction, 14(4), 550-564.

Zhang, L., Sun, X., and Xue, H. (2019). Identifying critical risks in Sponge City PPP projects using DEMATEL method: A case study of China. Journal of Cleaner Production, 226, 949-958.

Zhou, Y., Li, D., Jia, J., Li, X., Zhao, L., Sun, W., et al. (2017). Interparental conflict and adolescent internet addiction: The mediating role of emotional insecurity and the moderating role of big five personality traits. Computers in Human Behavior, 73, 470-478.

Zolkepli, I. A., Kamarulzaman, Y., and Kitchen, P. J. (2018). UNCOVERING PSYCHOLOGICAL GRATIFICATIONS AFFECTING SOCIAL MEDIA UTILIZATION: A MULTIBLOCK HIERARCHICAL ANALYSIS. Journal of Marketing Theory and Practice, 26(4), 412-430. 